\title{
Apresentação do Método Anátomo-Clínico de Faciometria Directa em Crianças com Objectivos Propedêuticos
}

\author{
Presentation of the Anatomical and Clinical Method of Direct Faciometrics \\ in Children with Propaedeutic Purpose
}

Ivo A. FURTADO ${ }^{1,2}$, Helena Roque AGOSTINHO ${ }^{3}$

Acta Med Port 2014 Jul-Aug;27(4):458-466

RESUMO

Introdução: Introduzimos o conceito de faciometria directa propedêutica, subjacente ao método de avaliação do crescimento da face infantil apresentado, com relevantes vantagens sobre outros métodos utilizados.

Material e Métodos: Observámos 102 crianças Caucasianas saudáveis, de ambos os sexos, até aos 14 anos (inclusive), que acederam à Consulta de Estomatologia Pediátrica do Centro Hospitalar de Lisboa-Norte, desde 1 de Maio de 2011 e durante um ano. Avaliámos o grau de crescimento facial e as suas características, baseados em medidas lineares e angulares obtidas a partir de pontos de referência situados na superfície da face. Realizámos registos sistemáticos de frente e perfil; tomámos medidas lineares com paquímetro digital e angulares com goniómetro digital. Usámos o método estatístico de aplicação de tabelas de correlação e do teste de ANOVA a dois factores.

Resultados: Apresentamos resultados e construímos curvas de crescimento.

Discussão: Verificámos haver um surto de crescimento ântero-posterior da face até aos 6 anos, que prossegue atenuado até aos nove anos. Dos 9 aos 12 anos verificou-se novo surto de crescimento, residual a partir desta idade. Não houve variações significativas nos valores médios etários angulares, nem diferenças de género no crescimento facial. O erro inter-observador foi de 0,62 mm para valores lineares e 2,65 graus para valores angulares.

Conclusões: Método fiável, sem imagem nem radiação, não invasivo, simples, económico e reprodutível. Recomendamos para utilização em Estomatologia Pediátrica e Pediatria, por constituir um recurso propedêutico que permite efectuar diagnóstico precoce de anomalias do crescimento facial da criança, susceptíveis de intercepção e correcção atempadas.

Palavras-chave: Antropometria; Anatomia; Criança; Cefalometria; Face.

\section{ABSTRACT}

Introduction: We introduce the concept of direct faciometrics with propaedeutic purpose, underlying the measurement of growth in infant face, with relevant advantages over other methods.

Material and Methods: We observed 102 healthy Caucasian children of both gender, aged up to 14 years (included) who accessed the consultation of Pediatric Stomatology of Lisboa-Norte Hospital Centre, from May 1, 2011 and during one year. We evaluated the degree of facial growth and its characteristics, based on linear and angle measurements obtained from reference points located on facial surface. Systematic records in front and profile were performed; linear and angle measures were noted with respectively a digital caliper and a digital goniometer. We used the statistical method of applying correlation tables and ANOVA test of two factors.

Results: We deliver results and constructed growth curves.

Discussion: We observed a growth spurt of anteroposterior face until the age of 6 , which continues attenuated until the aged of 9 . From 9 to 12 years old there has been a new growth spurt, which becomes residual from this age on. There were no significant changes in age angle mean values or gender differences in facial growth. The inter-observer error was $0.62 \mathrm{~mm}$ for linear values and 2.65 degrees for angle values.

Conclusions: This is a reliable method, without image or radiation, non-invasive, simple, inexpensive and reproducible. Recommended for use in Pediatric Dentistry and Pediatrics, constituting a semiological resource that allows an early diagnosis of facial growth abnormalities in children, and hence their timely interception and correction.

Keywords: Anthropometry; Anatomy; Child; Cephalometry; Face.

\section{INTRODUÇÃO}

O termo faciometria foi introduzido na literatura médica em 1996 por El-Mangoury, ${ }^{1}$ integrado no método cefalométrico não radiográfico que propunha, para utilização na análise facial. Na faciometria é efectuada uma avaliação visual da face do doente e realizadas medições através de procedimentos directos, como os que propomos, quer através de medições realizadas em fotografias, por meios manuais ou computadorizados. ${ }^{1-7}$ A faciometria directa propedêutica é uma técnica de mensuração vectorial, linear e angular realizada na superfície da face do doente, a partir de pontos antropométricos pré-definidos, que permite obter dados semiológicos importantes sobre a quantidade e características do crescimento facial das crianças. Como o próprio nome indica, as medições são feitas directamente no doente, e permitem confirmar evidências semiológicas, tendo por esse facto objectivos predominantemente propedêuticos.

A superfície do crânio e da face, nomeadamente o seu contorno, reflectem o padrão de crescimento. ${ }^{2-5}$

1. Serviço de Estomatologia. Hospital de Santa Maria. Centro Hospitalar de Lisboa Norte. Lisboa. Portugal.

2. Instituto de Anatomia. Faculdade de Medicina. Universidade de Lisboa. Lisboa. Portugal.

3. Consulta de Estomatologia Pediátrica. Serviço de Estomatologia. Hospital de Santa Maria. Centro Hospitalar de Lisboa Norte. Lisboa. Portugal.

Recebido: 19 de Dezembro de 2013 - Aceite: 28 de Abril de 2014 | Copyright @ Ordem dos Médicos 2014 
O estudo da organização intrínseca da face e da cavidade oral, da sua estrutura interior e exterior, e da função associada, constituem parte integrante da anatomia regional. A anatomia orofacial resulta de um fenómeno de crescimento e desenvolvimento celular pré-natal, e condiciona o crescimento e o desenvolvimento após o nascimento e até à idade adulta. ${ }^{8}$ Assim se justificam, por exemplo, no primeiro caso o aparecimento das malformações congénitas, ou no segundo, as perturbações do crescimento e desenvolvimento dos maxilares, associadas a problemas respiratórios. As anomalias anatómicas da face e/ ou da cavidade oral, traduzem-se frequentemente em desvios patológicos da normalidade (ex: fenda palatina), ou constituem fenómenos indutores de perturbação funcional, geradora de doença (ex: macroglossia).

O conhecimento precoce e exacto do diagnóstico (ex: detecção pré-natal de anomalia genética), ou de antecedentes familiares da doença, pode em alguns casos, impedir ou atenuar a ocorrência e o desenvolvimento do problema anátomo-clínico associado, através da introdução de medidas preventivas, interceptivas ou correctivas atempadas. O crescimento e desenvolvimento da face, sendo simultâneo ao desenvolvimento craniano, apresenta no entanto especificidades, que são objecto do nosso estudo detalhado.

O estudo da anatomia da face e da cavidade oral passa primeiramente pelo exame clínico da superfície, pelo Pediatra, Estomatologista ou Médico Dentista. Permite obter informações mensuráveis sobre parâmetros fundamentais de avaliação transversal e longitudinal da evolução do crescimento infantil, previamente ao pedido de exames imagiológicos. Hoje o clínico dispõe de meios tecnológicos, nomeadamente de imagem, não invasivos ou minimamente invasivos, que permitem obter resultados de excelência, e incluindo também a reprodução fiel das estruturas da face e da cavidade oral. Cada qual deve, no entanto, ser utilizado com critérios bem definidos de indicação clínica baseada na evidência científica, incluindo o custo-benefício, após adequada ponderação.

O sentido do crescimento normal da face da criança faz-se para baixo e para diante. É relevante saber-se que $60 \%$ do crescimento facial se faz até aos quatro anos, e que $90 \%$ decorre até aos 12 anos de idade. A avaliação do tipo facial faz-se através da cefalometria, antropometria e pela análise facial. A primeira avaliação do crescimento facial deve ser necessariamente clínica. Esta deve assumir-se como procedimento corrente e regular, no exame clínico da face concretamente em Pediatria ou em Estomatologia Pediátrica. $\mathrm{O}$ crescimento da face faz-se de modo distinto, consoante as localizações, tanto no andar médio como no inferior. No primeiro caso o crescimento é predominantemente condicionado por suturas, pese embora no segmento nasal haja crescimento cartilaginoso; no segundo caso, o crescimento no maxilar superior faz-se nas suturas e também por processos de aposição/ reabsorção óssea, havendo na mandíbula crescimento cartilaginoso no côndilo, e prevalecendo nas restantes localizações os fenó- menos de aposição/ reabsorção. ${ }^{9}$

A anatomia da superfície da face da criança fornece importantes indicadores do crescimento facial e de patologias que possam causar alterações do seu contorno. ${ }^{10-12}$ Sendo conhecidos os efeitos adversos das radiações ionizantes ${ }^{13,14}$ e a particular sensibilidade das crianças às mesmas, o pedido de exames imagiológicos, nomeadamente para o estudo do crescimento facial, deve ter indicações precisas: deve servir para confirmar o diagnóstico clínico, para programação de tratamento ortopédico ou ortodôntico, ou ser pedido por suspeição clínica de anomalia. O exame clínico deve ser o método de eleição, para avaliar o crescimento e o desenvolvimento orofacial da criança, até ao momento da indicação do exame complementar imagiológico. A face clínica tem particularidades, relativamente à área anatómica que integra. Assim, o terço superior da face clínica integra o segmento craniano que começa no ponto de implantação anterior do cabelo, situado no centro da região frontal, denominado Trichion e vai até à linha supra-ciliar. ${ }^{15-17}$

$\mathrm{Na}$ aplicação do método faciométrico directo é necessário padronizar os procedimentos e as medidas utilizadas. Farkas ${ }^{18}$ considera que a criança deve ser observada sentada em frente ao investigador. Propõe que sejam contemplados dois planos de observação (frente e perfil). O plano de Franckfurt deve coincidir com o plano horizontal. As medições lineares devem ser tomadas com um paquímetro digital e as angulares com um goniómetro digital. Farkas ${ }^{18}$ propôs igualmente a referência de 47 pontos antropométricos e a recolha de 132 medidas. Baseámo-nos em pontos propostos por Farkas, de que escolhemos os que considerámos mais representativos, tendo em vista o estudo da face clínica propriamente dita e correspondendo aos andares médio e inferior.

Considerámos as seguintes hipóteses de trabalho:

- O contorno da face infantil reflete o seu padrão de crescimento;

- Os pontos anatómicos antropométricos, podem ser utilizados para faciometria vectorial, linear e angular;

- Os parâmetros obtidos permitem quantificar e caracterizar o crescimento ocorrido;

- Revelam variações individuais;

- Permitem determinar desvios e anomalias de crescimento facial;

- A faciometria directa tem especial indicação propedêutica, sobretudo até à indicação do pedido de uma telerradiografia para cefalometria.

Este método tem ainda a vantagem de ser um método não invasivo, não havendo exposição da criança a radiações ionizantes, com preservação da imagem da criança, económico, fiável, reprodutível e de fácil execução. A partir da ciência antropométrica, iniciada por Albrecht Dürer (1471 - 1528), que estuda os caracteres mensuráveis do corpo humano, evoluiu-se para as medições gerais de estruturas da superfície corporal consignadas na morfometria de superfície e para as medições segmentares corporais, que entre outras regiões incluem a cabeça. ${ }^{19-22} \mathrm{O}$ desen- 
volvimento das Especialidades, que neste caso aliam a Anatomia Clínica à Estomatologia e à Medicina Dentária, e dada a região circunscrita tratada no caso presente, a face, começa a ser utilizado o termo faciometria, pela especificidade da técnica, em trabalhos internacionais. ${ }^{1,20,24,25}$ Consideramos que a utilização dos termos antropometria e/ ou morfometria, não traduzem a expressão da originalidade do método proposto de faciometria directa com objectivos propedêuticos. Trata-se de um procedimento de medição directa realizado a partir de pontos de referência localizados na superfície da face, como expressão superficial do contorno das estruturas subjacentes. O nosso espaço de investigação e a proposta deste método resulta do facto de ser primeiramente um instrumento de pesquisa semiológica e com relevante importância na propedêutica e não tanto na clínica ou terapêutica, razão pela qual, sendo o termo propedêutico, enquanto precursor da prática clínica propriamente dita, o mais adequado do vocabulário médico, considerámos relevante a sua introdução e difusão internacional, como contribuição científica dos autores.

São objectivos deste estudo:

- Introduzir o conceito de faciometria directa propedêutica;

- Propor um novo método de avaliação clínica do crescimento facial em crianças;

- Concluir sobre as vantagens do método apresentado face a outros métodos de utilização corrente e que suportam a indicação como um importante método semiológico a considerar.

\section{MATERIAL E MÉTODOS}

Em Maio de 2011, após a submissão do projecto de investigação à apreciação pela Comissão de Ética do Centro Hospitalar de Lisboa-Norte/ Hospital de Santa Maria (CHLN/HSM), deu-se início à Investigação. Foi obtido de- ferimento do Conselho de Administração, com a referência PCA - 29. Jul. 2011 - 0569.

Foi contemplada a realização de um estudo observacional transversal de grupos de crianças de diferentes extractos etários, da Consulta de Estomatologia Pediátrica do $\mathrm{CHLN} / \mathrm{HSM}$, por dois investigadores, com periodicidade semanal e em dois dias diferentes, cabendo um dia a cada um. As crianças observadas, saudáveis, de ambos os sexos, foram admitidas até aos 14 anos (inclusive) por ordem de acesso à Consulta de Estomatologia Pediátrica. A cada uma foi atribuído um número de ordem de observação, tendo sido observadas 102 crianças Caucasianas tendo em vista prevenir distorções de resultados faciométricos que pudessem estar relacionados a variações étnicas (Fig. 1).

Podemos observar grupos etários proporcionalmente equilibrados relativamente ao género e com o maior número entre os 8 e os 11 anos.

A criança era introduzida na Consulta de Estomatologia Pediátrica, pela Assistente Dentária, que efectuava o registo dos indicadores estato-ponderais. Foi utilizada uma balança convencional da marca Jofre, modelo com alcance de $150 \mathrm{Kg}$ e com craveira incorporada. Os pais ou o tutor da criança, eram informados pelos investigadores, sobre os objectivos do trabalho a desenvolver, com explicação da importância da sua participação no estudo em curso, tendo em vista a obtenção do consentimento informado. As condições de observação foram as de um Gabinete de Estomatologia do Serviço, padronizado de acordo com as normas internacionais.

$\mathrm{Na}$ consulta adoptaram-se os procedimentos seguintes: Como medida sistemática foi efectuado o exame clínico da face da criança sentada, colocada em posição de frente e de seguida de perfil direito. O plano horizontal ficava em paralelo com o plano de Franckfurt (plano transversal que inclui o pré-tragus e o ponto mais inferior do rebordo

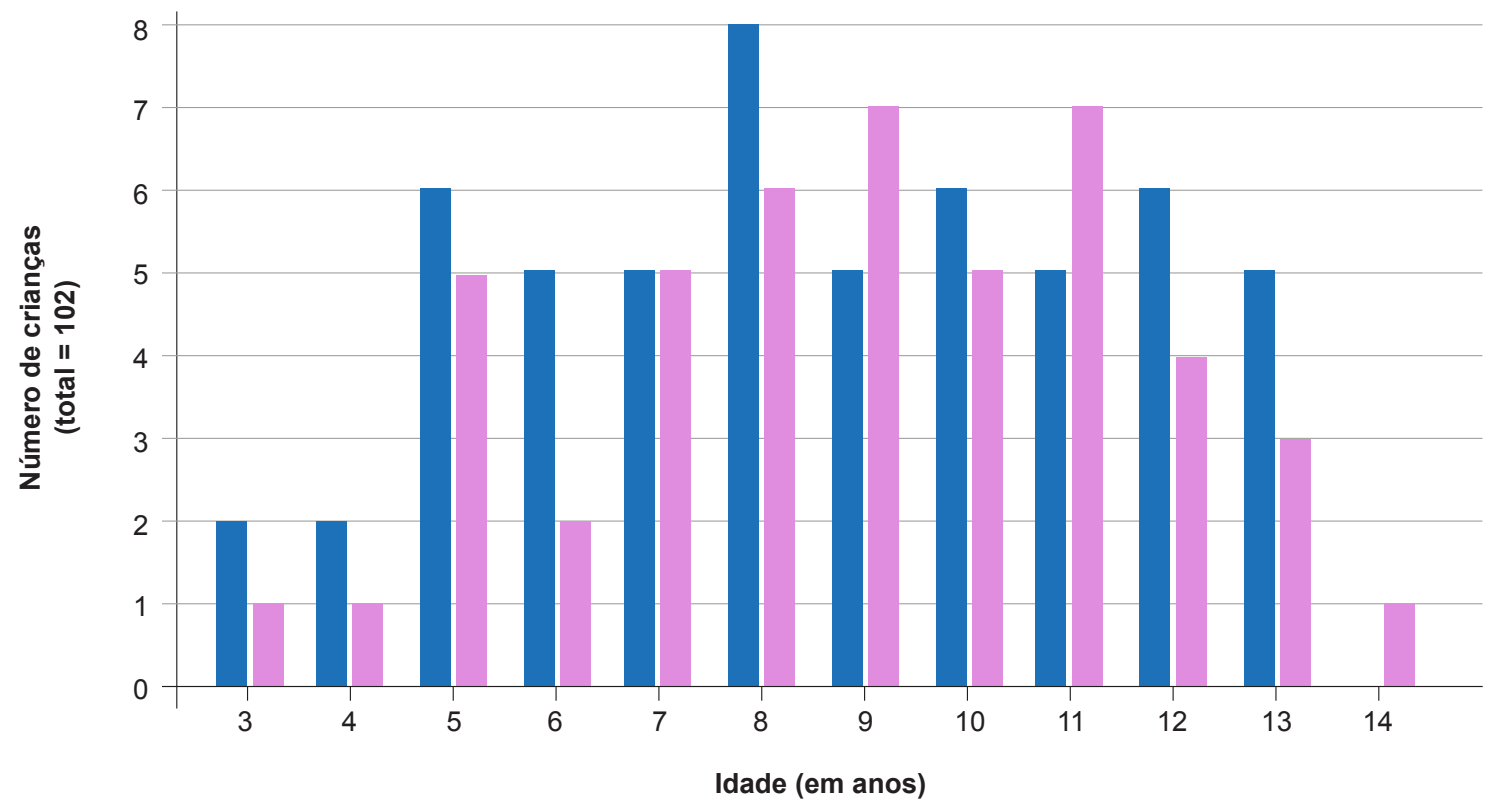


orbitário). A escolha dos pontos antropométricos para faciometria contemplou a face propriamente dita, excluindo o 1/3 superior da face clínica (integrada no crânio) e a região do nariz, que em ambos os casos, embora com relação íntima, são objecto de estudo de outras especialidades (ORL,Cirurgia Plástica, etc). O terço superior da face foi considerado menos importante ${ }^{9}$ por ser altamente variável e condicionado pela linha de implantação capilar. Foram escolhidos os pontos antropométricos da superfície da face considerados mais representativos da projecção cutânea do contorno ósseo subjacente e da globalidade do contorno da face, fáceis de determinar, e em número mínimo indispensável aos objectivos propostos. Estes pontos são suportados por várias investigações relevantes nesta área do conhecimento. ${ }^{20-22}$ Seguidamente definimos os pontos registados e dois outros que embora não escolhidos para recolha de dados, eram relevantes para melhor integração do tema: o Trichion ( $\mathrm{Tr}$ ) e a Glabela (G). O Trichion é o ponto de implantação anterior do cabelo, situado no centro da região frontal. A Glabela localiza-se no processo frontal anterior, entre as regiões supra-ciliares. Seguem-se as definições dos pontos considerados para recolha de dados: $O$ Nasion cutâneo ( $\mathrm{N}$ ) é o correspondente cutâneo ao Nasion (ponto mediano mais profundo de união naso-frontal) situado entre os processos supraciliares. O Porion cutâneo (Po ') é o ponto cutâneo mais lateral e superior do canal auditivo externo. Escolhido por ser um ponto de localização relativamente constante da base craniana, servindo de referência para o crescimento facial. O ponto Orbitário cutâneo (Or ') é ponto situado mais inferiormente no contorno da órbita, sendo importante na avaliação das assimetrias da face.

O ponto Zigomático cutâneo (Zỉ) situa-se na posição mais lateral do processo zigomático. É um ponto fundamental para a determinação da largura facial. O ponto Subnasal (Sn) é o ponto mediano do ângulo da base da columela, onde o bordo inferior do septo nasal se une à base de inserção do lábio superior. O Stomium (Sto) é o ponto de união central dos lábios (superior e inferior), e constitui um elemento importante na avaliação da face estética. O Pogonium cutâneo $\left(\mathrm{Pg}^{`}\right)$ é o ponto mais anterior do contorno mediano do mento. O ponto Mentoniano ou Mental cutâneo (Me') é o ponto mais inferior do contorno do mento. O Gonion cutâneo (Go') é um ponto construído pela união da linha tangente à margem posterior do ramo ascendente da mandíbula, e a tangente ao bordo inferior do corpo mandibular. Seguiram-se as recomendações Internacionais para a realização de estudos antropométricos clássicos..$^{20,21,26-30}$

Tendo em vista reduzir a probabilidade de erro inter-examinadores, foi efectuado o ensaio prévio da técnica e a calibragem interpessoal pelo método comparativo de duplicação de um registo linear e de um registo angular (contemplando todos os parâmetros), tendo sido rejeitadas as medições, até que se obtivesse um nível de reprodutibilidade superior a $95 \%$, tanto nos registos lineares quanto angulares. Este controlo manteve-se durante todos os registos do estudo realizado.

Para aumentar a precisão, na localização dos pontos a determinar, procedeu-se à palpação prévia à mensuração, com a marcação dos pontos com caneta de marcação dérmica. A partir dos pontos considerados e previamente definidos, foram tomadas medidas lineares e angulares directas, respectivamente com paquímetro digital DCA 150B Velleman e goniómetro digital modelo Angelo (Fig.s 2a, 2b), com registo na ficha de investigação, respectivamente em milímetros e graus. Procedeu-se à familiarização da equipa e de cada doente com os instrumentos a utilizar, de modo a prevenir erro ou dano durante a utilização dos instrumentos e concretamente do paquímetro ou do goniómetro. Para evitar distorções e erros de medição, procurou-se não pressionar a pele, com as pontas do paquímetro.

A Fig. 2a ilustra a tomada de medidas lineares de frente, com adequado posicionamento da cabeça da criança e com anotação à margem, das medidas a efectuar. A Fig. $2 \mathrm{~b}$ mostra por sua vez a tomada de medidas angulares,

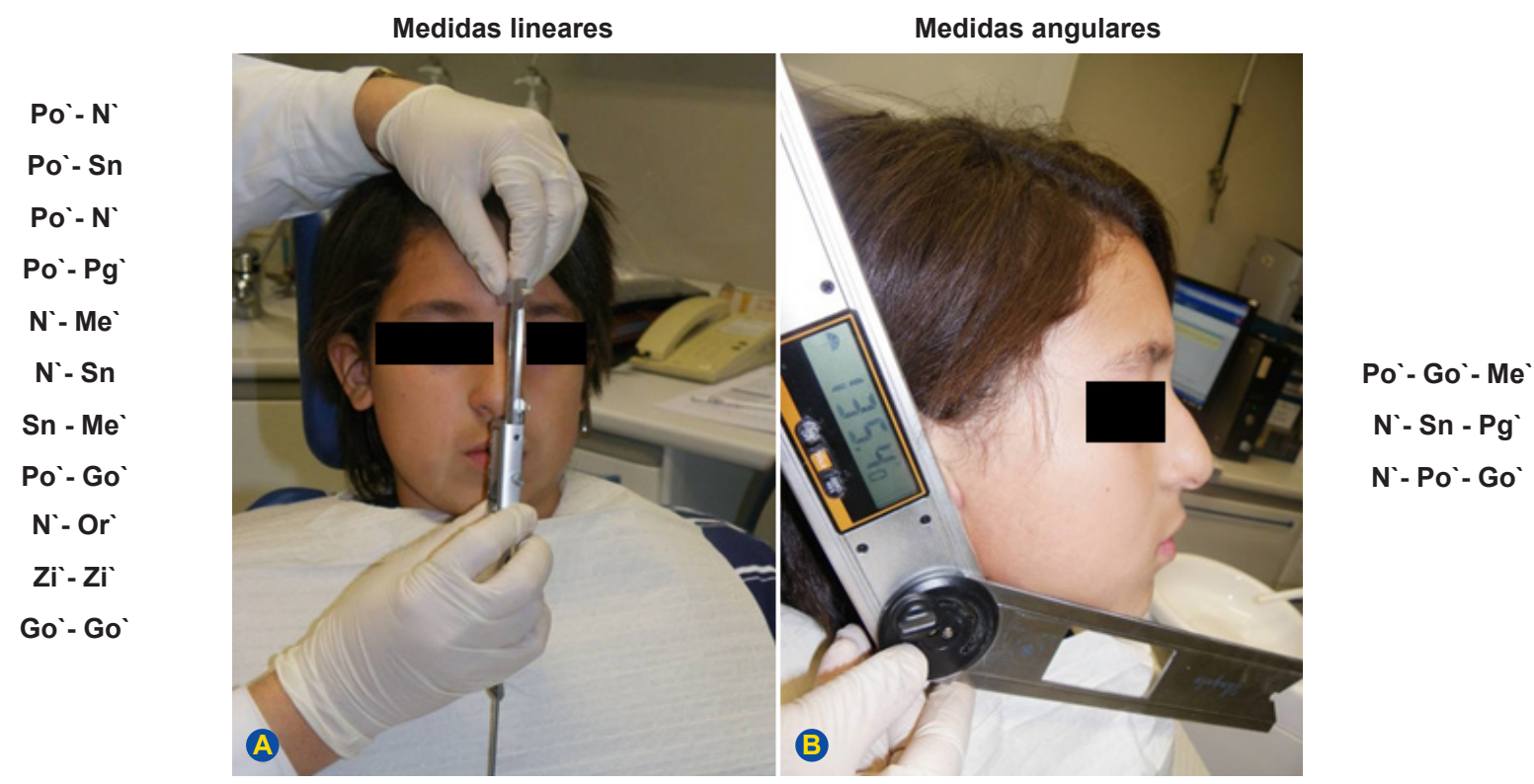

Figura 2 - Recolha metódica e sistemática de dados clínicos, incluindo as medidas lineares (A) e angulares (B), acima referidas 
contempladas em criança vista de perfil e com as medições a efectuar, inscritas na margem oposta da figura.

$\mathrm{Na}$ tomada de medidas lineares, o Porion cutâneo foi considerado um ponto de referência de posicionamento relativamente constante, a partir do qual foram aferidos os ganhos de crescimento. Para determinação do comprimento da base do crânio considerou-se a medida linear entre o porion cutâneo e a glabela (nasion); para a determinação do comprimento maxilar, a medida linear entre o porion cutâneo e o ponto subnasal (Sn) e para o comprimento mandibular a distância medida em milímetros entre o porion cutâneo e o pogonion cutâneo. Os valores angulares recolhidos incluíram a determinação do sentido do crescimento verificado. O registo do ângulo do perfil anterior da face foi determinado pela anotação do valor obtido na união dos pontos Nasion cutâneo, Subnasal e Pogonion cutâneo. Em ambos os casos as medidas contemplaram o contorno superficial, que reflete não apenas o sentido do crescimento ósseo subjacente, mas também o perfil dos tegumentos, importante na avaliação estética e funcional, de que o stomium é considerado um ponto referencial destacado.

As medidas da simetria facial foram tomadas por medições realizadas de frente entre o Nasion cutâneo e o Ponto Orbitário cutâneo de cada lado. Foram identificadas algumas assimetrias decorrentes de perturbações do desenvolvimento, que se procurou identificar precocemente, visando o tratamento interceptivo e correctivo, atempados.

As fichas dos doentes observados constam da base de dados do Centro Hospitalar de Lisboa-Norte/Hospital de Santa Maria e os dados foram objecto de recolha pelos autores, inseridos em folha Excel e analisados em programa SPSS 18. Foi efectuado o tratamento estatístico dos dados com a aplicação de tabelas de correlação e do teste de ANOVA a dois factores. Assumiu-se um nível de significân- cia $<0,05$. Os testes estatísticos utilizados foram escolhidos de acordo com o critério do analista e tendo em conta o tipo de variáveis e a escala com que se trabalhava. Quando houve necessidade de medir o grau de associação entre variáveis, utilizaram-se as tabelas de correlação. Nos casos em que se compararam grupos e diferenças de médias entre grupos, foi aplicado o teste de ANOVA a dois factores.

\section{RESULTADOS}

Foi testada a reprodutibilidade do método, tendo sido obtido um nível de erro inter-observador de 0,62 $\mathrm{mm}$ para os valores lineares e de 2,65 graus para os valores angulares.

Obtivemos os seguintes resultados para o crescimento médio da base do crânio no sentido ântero-posterior, em milímetros, para os diferentes grupos etários: 3 anos = 101,$1 ; 4$ anos $=102,2 ; 5$ anos $=106,56 ; 6$ anos $=109,33 ; 7$ anos $=110,08 ; 8$ anos $=112,54 ; 9$ anos $=113,59 ; 10$ anos $=115,27 ; 11$ anos $=118,55 ; 12$ anos $=121,63 ; 13$ anos $=$ 122,$19 ; 14$ anos $=122,88$.

Para a maxila, o crescimento ântero-posterior obteve os seguintes parâmetros médios, em milímetros, para os mesmos grupos etários: 3 anos $=99,34 ; 4$ anos $=102,1 ; 5$ anos $=102,93 ; 6$ anos $=109,18 ; 7$ anos $=112,5 ; 8$ anos $=114,36$; 9 anos $=114,79 ; 10$ anos $=117,69 ; 11$ anos $=119,92 ; 12$ anos $=124,06 ; 13$ anos $=125,25 ; 14$ anos $=128,85$.

Para a mandíbula, os resultados médios obtidos, em milímetros, para o crescimento ântero-posterior, nas mesmas crianças e grupos etários considerados, foram os seguintes: 3 anos $=104,74 ; 4$ anos $=106,12 ; 5$ anos $=$ 113,$53 ; 6$ anos $=115,54 ; 7$ anos $=115,89 ; 8$ anos $=121,34$; 9 anos $=124,35 ; 10$ anos $=124,75 ; 11$ anos $=132,22 ; 12$ anos $=136,44 ; 13$ anos $=137,1 ; 14$ anos $=138,78$.

Construímos as curvas de crescimento apresentadas nas Fig.s 3, 4 e 5.

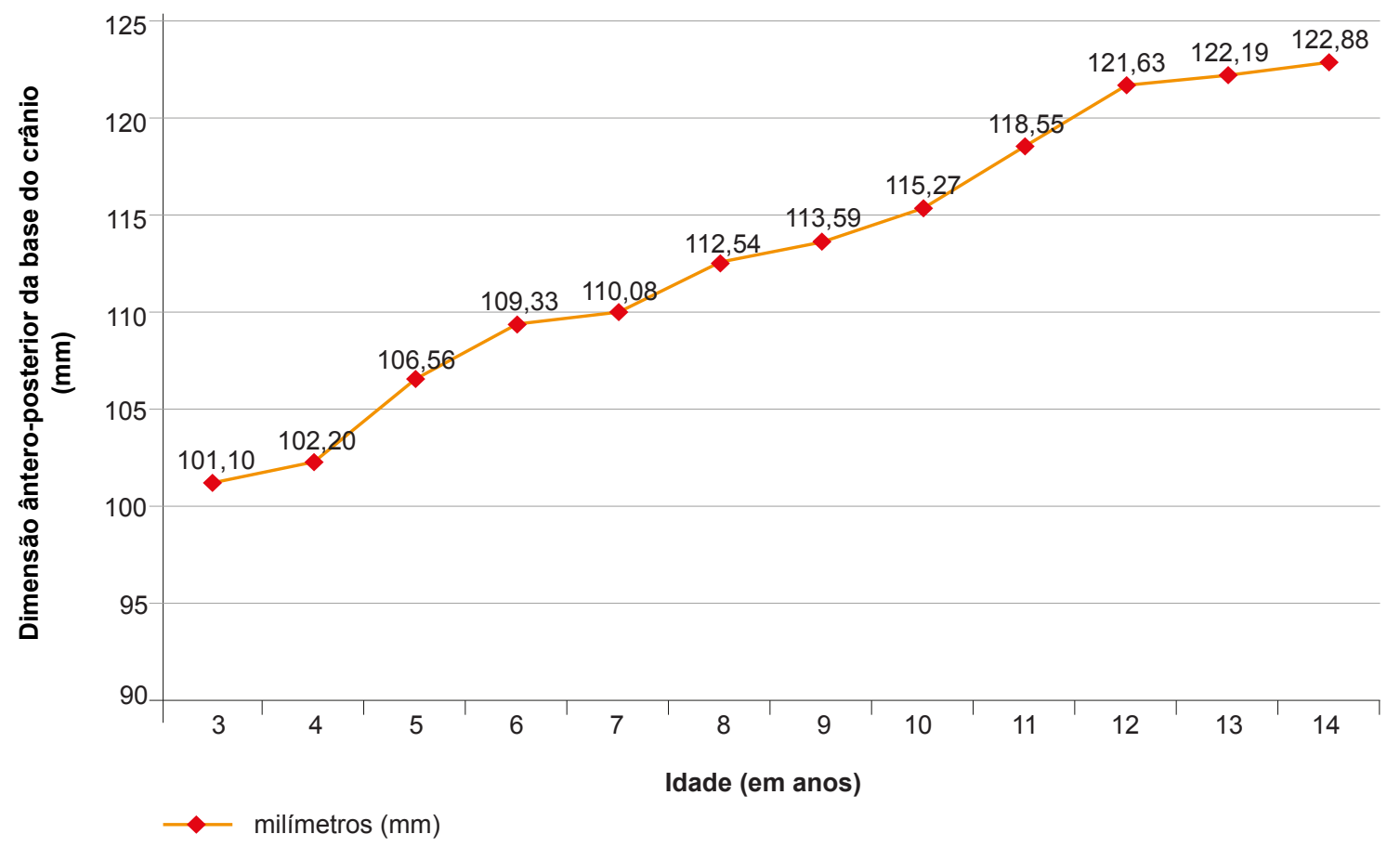

Figura 3 - Curva de crescimento ântero-posterior da base do crânio 


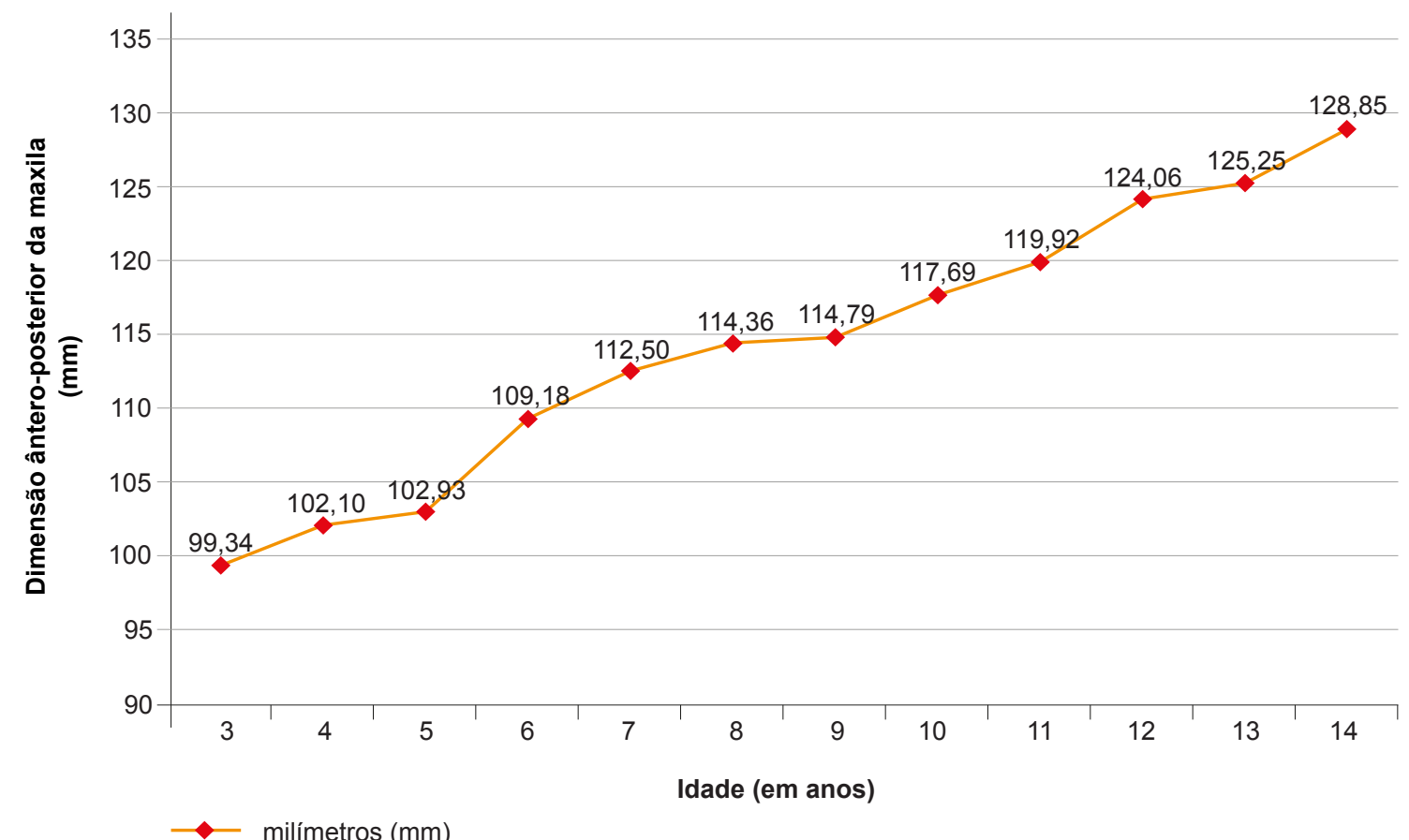

Figura 4 - Curva de crescimento ântero-posterior da maxila

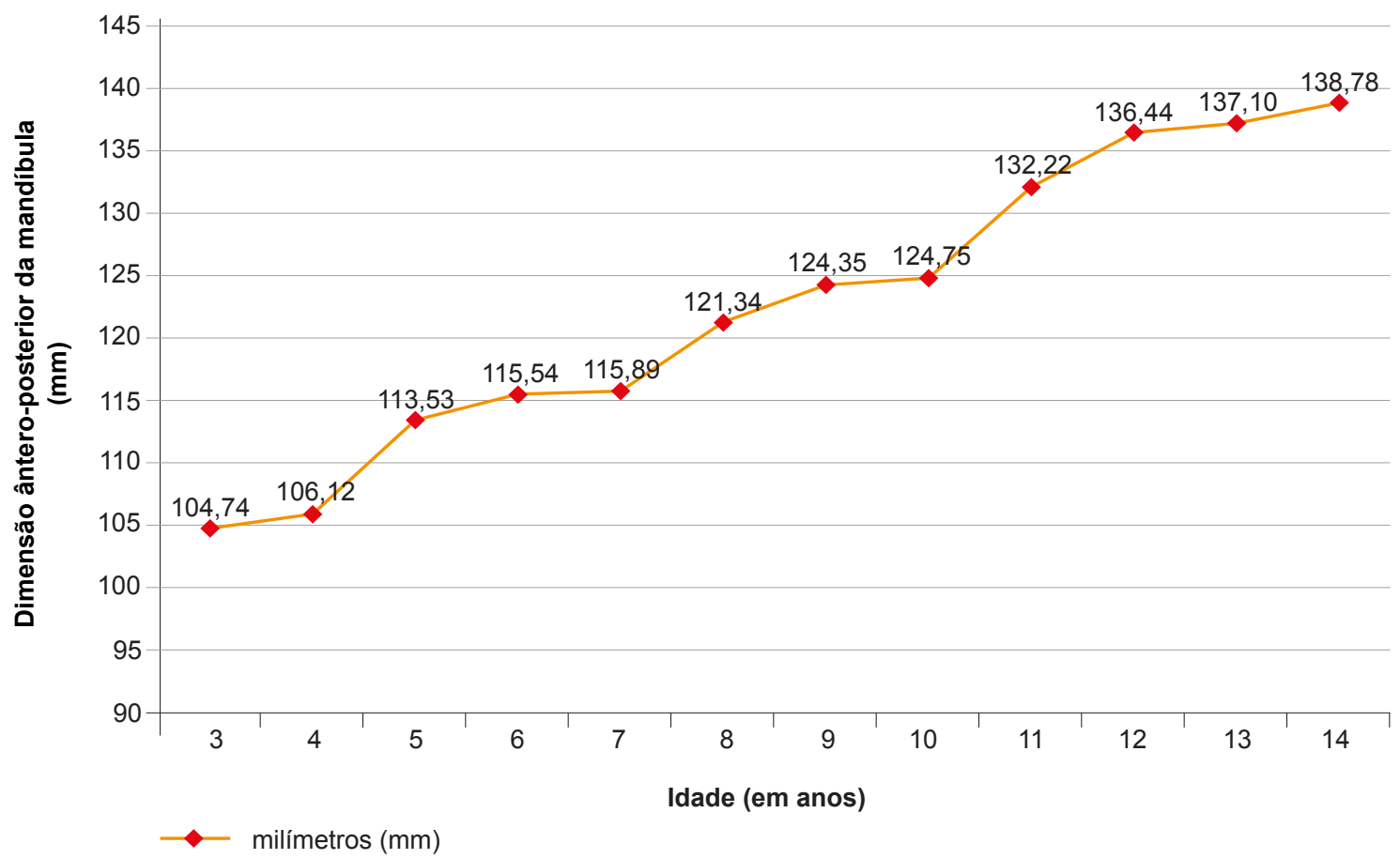

Figura 5 - Curva de crescimento ântero-posterior da mandíbula

Os valores médios obtidos, em milímetros, para o crescimento em altura do terço médio da face nos grupos etários das crianças estudadas, foram os seguintes: 3 anos $=45,78 ; 4$ anos $=46,32 ; 5$ anos $=49,59 ; 6$ anos $=50,74$; 7 anos $=53,2 ; 8$ anos $=55,2 ; 9$ anos $=55,67 ; 10$ anos $=$ 55,$37 ; 11$ anos $=55,87 ; 12$ anos $=59,86 ; 13$ anos $=62,52$; 14 anos $=61,79$. Para o crescimento em altura do terço inferior da face, nas mesmas crianças os valores médios obtidos, em milímetros, para os grupos etários considerados, foram: 3 anos $=53,52 ; 4$ anos $=55,98 ; 5$ anos $=56,54$;
6 anos $=59,27 ; 7$ anos $=59,64 ; 8$ anos $=65,81 ; 9$ anos $=$ 63,$28 ; 10$ anos $=65,35 ; 11$ anos $=66,33 ; 12$ anos $=65,03$; 13 anos $=69,15 ; 14$ anos $=69,03$ (Fig. 6).

Foram registados os seguintes valores médios da altura facial anterior, em milímetros, para as mesmas crianças: 3 anos $=96,76 ; 4$ anos $=99,58 ; 5$ anos $=104,68 ; 6$ anos $=$ 106,$38 ; 7$ anos $=110,33 ; 8$ anos $=115,51 ; 9$ anos $=116,09$; 10 anos $=116,29 ; 11$ anos $=120,16 ; 12$ anos $=124,68 ; 13$ anos $=125,22 ; 14$ anos $=125,87$. Para a altura facial posterior obtiveram-se os seguintes valores médios etários, em 
milímetros: 3 anos $=48,07 ; 4$ anos $=50,77 ; 5$ anos $=53,35$; 6 anos $=55,15 ; 7$ anos $=56,93 ; 8$ anos $=57,7 ; 9$ anos $=$ 57,$73 ; 10$ anos $=57,87 ; 11$ anos $=59,46 ; 12$ anos $=60,89$; 13 anos $=67,69 ; 14$ anos $=69,73$.

O ângulo da base do crânio (medido em graus) obteve os seguintes registos de valores médios etários: 3 anos $=$ $86 ; 4$ anos $=79,4 ; 5$ anos $=98,49 ; 6$ anos $=95,51 ; 7$ anos $=$ 86,$22 ; 8$ anos $=88,53 ; 9$ anos $=96,12 ; 10$ anos $=92,79 ; 11$ anos $=93,04 ; 12$ anos $=97,58 ; 13$ anos $=98,78 ; 14$ anos $=$ 96,5 .

O ângulo médio etário obtido para a mandíbula (medido em graus) obteve os seguintes valores: 3 anos $=128,83$; 4 anos $=120,92 ; 5$ anos $=124,75 ; 6$ anos $=129,34 ; 7$ anos $=130,51 ; 8$ anos $=124,99 ; 9$ anos $=125,63 ; 10$ anos $=$ 126,$78 ; 11$ anos $=128,41 ; 12$ anos $=125,52 ; 13$ anos $=$ 134,$76 ; 14$ anos $=130,05$.

Os valores médios etários obtidos para o ângulo (medido em graus) do perfil anterior da face (tomado na união dos pontos Nasion cutâneo, Subnasal e Pogonion cutâneo), foram os seguintes: 3 anos $=147,96 ; 4$ anos $=146,48 ; 5$ anos $=149,58 ; 6$ anos $=149,66 ; 7$ anos $=146,06 ; 8$ anos $=$ 147,$56 ; 9$ anos $=151 ; 10$ anos $=150,41 ; 11$ anos $=152,27$; 12 anos $=146,06 ; 13$ anos $=149,19 ; 14$ anos $=146,53$.

As medidas da simetria facial tomadas, não demonstraram haver diferenças estatisticamente significativas.

\section{DISCUSSÃO}

As curvas de crescimento no sentido ântero-posterior da base do crânio e da face (Fig.s 3, 4 e 5), revelaram a existência de um surto de crescimento até aos seis anos, seguido de um crescimento progressivo, embora menor, até aos nove anos. Este resultado é diferente do obtido por Meredith (1949), que referiu que $60 \%$ do crescimento da face está realizado aos quatro anos. Assim os nossos resultados apontam para um maior espaço de intervenção preventiva, permitindo actuar sobre as possíveis causas de perturbação do crescimento, nomeadamente factores respiratórios, incluindo os alérgicos. Entre os 9 e os 12 anos de idade houve um novo surto de crescimento ântero-posterior da face, o qual se tornou residual acima desta idade, nas crianças estudadas. O tamanho alcançado aos 14 anos no sentido ântero-posterior foi de $122,88 \mathrm{~mm}$ para a base do crânio, $128,85 \mathrm{~mm}$ para a maxila e $138,78 \mathrm{~mm}$ para a mandíbula.

Os valores médios etários da altura do terço médio da face apresentaram em todas as idades, um tamanho menor que os do terço inferior. $O$ crescimento de ambos foi simultâneo e equivalente, atingindo, aos 14 anos, $61,79 \mathrm{~mm} e$ 69,03 $\mathrm{mm}$ respectivamente (Fig. 6).

A altura facial anterior e posterior mostrou ter um crescimento pubertário entre os 12 anos e os 14 anos. Aos 14 anos a altura facial no sector anterior atingiu $125,87 \mathrm{~mm}$ e $69,73 \mathrm{~mm}$ no sector posterior.

Não houve variações significativas no valor médio angular obtido em cada idade, para a base do crânio, mandíbula ou para o perfil da face. Também não foram encontradas diferenças de género no crescimento facial das crianças estudadas, em todos os parâmetros considerados.

As afirmações precedentes, decorrentes da análise dos dados que permitiram construir as curvas de crescimento a partir de dados vectoriais, lineares e angulares, confirmam as seguintes hipóteses de trabalho:

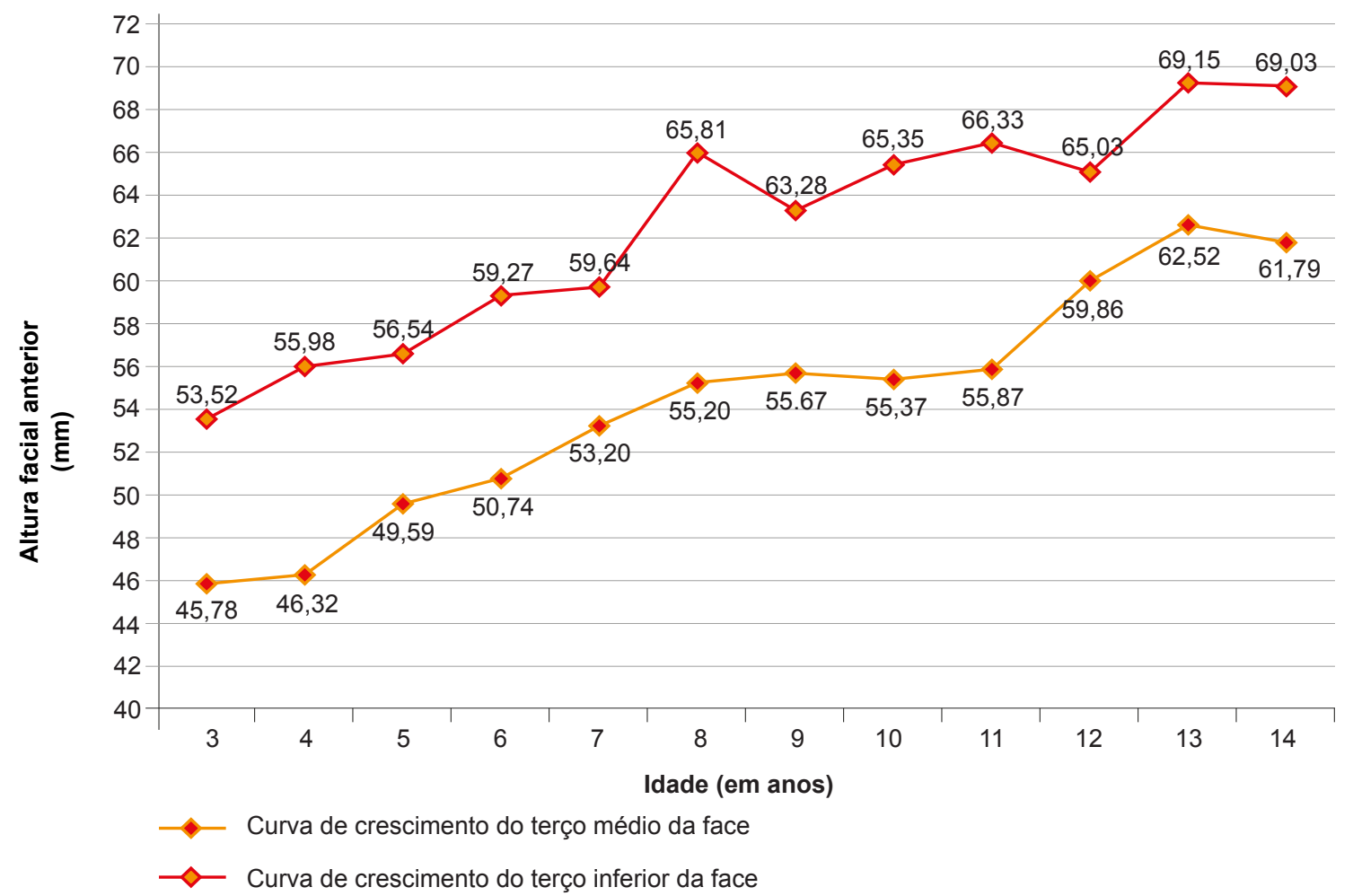

Figura 6 - Curva comparativa do crescimento em altura dos terços, médio e inferior da face 
- o contorno da face infantil reflete o seu padrão de crescimento;

- os pontos anatómicos antropométricos, podem ser utilizados para faciometria vectorial, linear e angular;

- os parâmetros obtidos permitem quantificar e caracterizar o crescimento ocorrido;

- revelam variações individuais e

- permitem determinar desvios e anomalias de crescimento facial.

Devido ao número restrito de crianças de cada grupo etário, as diferenças de género foram determinadas apenas na globalidade do crescimento e nas médias obtidas nos valores angulares do perfil anterior da face.

A ausência de diferenças estatisticamente significativas nas medidas da simetria facial anotadas era expectável, ${ }^{30,31}$ já que, tratando-se de crianças saudáveis, não era esperada a ocorrência de assimetrias durante o crescimento.

A técnica de faciometria tem escasso número de publicações ${ }^{1-7,33,34}$ e não encontrámos referência de indicadores de crescimento em crianças, o que constitui uma mais-valia da nossa investigação. O nível de reprodutibilidade em posição de autoequilíbrio obtido por Sollow e Tallgreen ${ }^{33}$ registou uma margem de erro de 2,48 graus, que não difere muito do valor angular obtido por nós (2,65 graus). Segundo Nanda e Ghosh ${ }^{33}$ a rígida atenção às normas do tecido duro não resulta em equilíbrio e harmonia da face, sendo estes últimos elementos os que devem constituir o objectivo principal do tratamento. Para isso, segundo Vaden, ${ }^{33}$ devem ser considerados os três factores que influenciam o equilíbrio facial ou a sua ausência: a posição dos dentes, o padrão esquelético e as dimensões do tecido mole aonde se enquadra a aplicação da faciometria. A constante evolução da ciência comporta o desafio da procura de novos conceitos que incluem, em muitos casos, o desenvolvimento de vertentes especializadas de técnicas estabelecidas, como é o caso da proposta presente, que se preconiza como método complementar ao exame objectivo da face infantil. El-Mangoury ${ }^{1}$ estabeleceu o método de faciometria, sendo hoje os seus trabalhos uma referência para a avaliação da estética facial e das suas proporções. ${ }^{19,20} \mathrm{O}$ método que propomos tem a vantagem de ser mais simples, porquanto utiliza instrumentos de custos tendencialmente nulos, de fácil manuseamento e transporte, podendo ser aplicados tanto em gabinete clínico de Estomatologia, Medicina Dentária ou Pediatria, como em estudos epidemiológicos ou de saúde escolar. É um método seguro, sendo isento de radiações, e aplicável a um estrato etário de população particularmente sensível às mesmas, podendo servir de meio de avaliação corrente do crescimento facial em fases anteriores à indicação da imagiologia.

Já demonstrámos que é um método fidedigno, na medida em que com uma equipa treinada conseguimos obter um nível de reprodutibilidade elevado (erro inter-observador de 0,62 $\mathrm{mm}$ para valores lineares e de 2,65 graus para valores angulares). Relativamente aos estudos recentes de fotogramometria de Othman ${ }^{6}$ e Deli, ${ }^{7}$ o método que preconi- zamos tem a vantagem de preservar a imagem da criança, facto que constitui em muitos casos uma preocupação dos pais. Deste modo se comprova a última hipótese de trabaIho colocada - a faciometria directa tem especial indicação propedêutica, sobretudo até à indicação do pedido de uma telerradiografia para cefalometria.

O nosso estudo teve reconhecidas limitações decorrentes do número de crianças em cada grupo etário e da impossibilidade de logo à partida realizar um estudo longitudinal, que seria desejável quando se trata de avaliar o crescimento. Para obviar esta limitação estudámos vários grupos etários de ambos os géneros. Era importante validar o método, contemplar a avaliação da indicação e das vantagens de um método que pretendemos introduzir como rotina na nossa Consulta de Estomatologia Pediátrica, constituindo o primeiro passo de abertura de uma de investigação de crescimento da face infantil não apenas na população Caucasiana, mas sobretudo para utilização no estudo das pertubações morfológicas e malformativas da face infantil. A escassez de trabalhos publicados é apelativa a que haja um esforço concertado de investigação de âmbito internacional, nesta área.

Finalmente, face ao que acabámos de expor, consideramos atingidos os objectivos imediatos deste estudo, de introdução do conceito de faciometria directa propedêutica como fundamento da implementação de um novo método de avaliação clínica do crescimento facial em crianças com vantagens face a outros métodos de utilização corrente e que suportam a indicação como um importante método semiológico a considerar. Porém, consideramos que o método que propomos carece ainda de maior desenvolvimento, pela utilização nas diferentes vertentes em que possa ser aplicado, em semiologia clínica geral da face em crianças saudáveis, no estudo de defeitos ósseo-tegumentares associados a perturbações do desenvolvimento, doenças metabólicas ou outras doenças sistémicas, ou mesmo de estudos de caracterização morfológica da face de populações que possam vir a ser estudadas.

\section{CONCLUSÕES}

Assim, concluímos que:

- o contorno da face infantil reflete o seu padrão de crescimento;

- os pontos anatómicos antropométricos, podem ser utilizados para faciometria vectorial, linear e angular;

- os parâmetros obtidos permitem quantificar e caracterizar o crescimento ocorrido;

- este é um método fiável, isento de imagem e de radiação, não invasivo, simples, económico e reprodutível.

Pelas razões apontadas, preconizamos que o método seja utilizado em Clínica Pediátrica, nomeadamente em Pediatria do Desenvolvimento, em Estomatologia Pediátrica e também em Medicina Dentária. É uma acrescida mais-valia no exame semiológico, permitindo o diagnóstico precoce de desvios de crescimento anatómico da face infantil, susceptíveis de intercepção e correcção atempadas. Vai 
ao encontro do desejo de alguns pais que pretendem preservar, na medida do possível, a exposição da imagem da criança e ao mesmo tempo é um instrumento indispensável à boa prática na avaliação do crescimento da face infantil.

\section{AGRADECIMENTOS}

À assistente dentária Leocádia Carvalho, a quem devemos o suporte básico de apoio à realização do método (recepção e orientação na admissão da criança, preparação de material e medição estato-ponderal de cada doente), agradecemos a profissional e competente colaboração

\section{REFERÊNCIAS}

1. El-Mangoury NH, Mostafa YA, Rasmy EM, Salah A. Faciometrics: a new syntax for facial feature analysis. Int J Adult Orthod Orthog Surg. 1996;11:71-82.

2. Bazmi BA, Zahir S. A cross-sectional study of soft tissue facial morphometry in children of West Bengal. Contemp Clin Dent. 2013;4:42-7.

3. Tartaglia GM, Dolci C, Sidequersky FV, Ferrario VF, Sforza C. Soft tissue facial morphometry before and after total oral rehabilitation with implantsupported prostheses. J Craniofac Surg. 2012;23:1610-4

4. Singh GD, Hodge MR. Bimaxillary morphometry of patients with class II division 1 malocclusion treated with twin block appliances. Angle Orthod. 2002;72:402-9.

5. Singh GD, McNamara JA Jr, Lozanoff S. Finite-element morphometry of soft tissues in prepubertal Korean and European-Americans with Class III malocclusions. Arch Oral Biol. 1999;44:429-36.

6. Othman SA, Ahmad R, Mericant AF, Jamaludin M. Reproducibility of facial soft tissue landmarks on facial images captured on a 3D camera. Aust Orthod J. 2013;29:58-65.

7. Deli R, Gioia ED, Galantucci LM, Percoco G. Accurate facial morphologic measurements using a 3-camera photogrammetric method. J Craniofac Surg. 2011;22:54-9.

8. Andrade KC, Souza SB, Szarfarc SC. Desenvolvimento neuromotor e dentição de crianças atendidas em serviços públicos de saúde do Brasil, no primeiro ano de vida. Rev Bras Crescimento Desenvolv Hum. 2007;17:37-44

9. Ustrell-Torrent JM. Manual de Ortodoncia. Barcelona: Publicacions Universitat de Barcelona; 2011. p. 96-117.

10. Farkas LG, Deutsch CK. Anthropometric determination of craniofacial morphology. Am J Med Genet. 1996;65:1-4.

11. Allanson JE. Objective techniques for craniofacial assessment: what are the choices? Am J Med Genet. 1997;70:1-5

12. Ward RE, Jamilson PL, Farkas LG. Craniofacial variability index: a simple measure of normal and abnormal variation in the head and face. Am J Med Genet. 1998;80:232-40.

13. Whaites E. Princípios de Radiologia Odontológica. $4^{\mathrm{a}}$ ed. Elsevier; 2007. p. 25-8

14. Miles DA, Van Dis ML, Williamson GF, Jensen CW. Radiographic imaging for the dental team. 4a ed. Elsevier; 2009. p. 107-24.

15. Arnett GW, Bergman RT. Facial keys to orthodontic diagnosis and treatment planning. Part II. Am J Orthod Dentofacial Orthop. 1993;103:305411.

16. Almeida RC, Almeida RH. Assimetria facial no exame clínico da face. Ortodontia. 1999;32:82-6.

17. Costa LA, Fernandes GO, Kanazawa LS, Miranda JG, Pretti H. Análise facial - uma revisão da literatura. J Bras Ortodon Ortop Facial. 2004;9:171-6

18. Farkas LG. Anthropometry of the head and face. In: Farkas LG, editor. Anthropometry of the head and face. 2a ed. New York: Raven Press; 1994. p. 3-56. prestada. Agradecemos a José Monteiro a cedência do indispensável suporte estatístico do trabalho.

\section{CONFLITO DE INTERESSES}

Os autores declaram que o presente artigo não apresenta conflito de interesses.

\section{FONTES DE FINANCIAMENTO}

Os autores declaram que o presente artigo não foi suportado por qualquer apoio financeiro.

19. Santos R, Fujão C. Antropometria. [consultado 2014 Mar 31] Disponíve em http://www.professores.uff.br/cecilia/disciplinas/Texto-Antropometria.pdf .

20. Ramires RR, Ferreira LP, Marchesan IQ, Cattoni DM, Silva MA. Proposta para determinação do tipo facial a partir da antropometria. J Soc Bras Fonoaudiol. 2011;23:195-200

21. Farkas LG, Posnick JC, Hreczko TM. Growth patterns of the nasolabia region: a morphometric study. Cleft Palate Craniofac J. 1992;29:318-24.

22. Farkas LG, Posnick JC, Hreczko TM. Growth patterns of the face: a morphometric study. Cleft Palate Craniofac J. 1992;29:308-15.

23. Moate SJ, Geenty JP, Shen G, Darendeliler MA. A new craniofacial diagnostic technique: the Sydney diagnostic system. Am J Orthod Dentofacial Orthop. 2007;131:334-42.

24. Morihisa O, Brangeli L. Avaliação comparativa entre agrabilidade facial, proporção áurea e padrão facial 2006. [consultado 2014 Fev 11]. Disponível em http://www.ibict.metodista.br.

25. Amaral C, Sollitto KC, Santos TM, Parizi AG, Oliveira A, Straioto F. Características físicas e bucais em doentes portadores da Síndrome do X-Frágil. Rev Assoc Paul Cir Dent. 2012;66:128-34

26. Ward RE, Jamison PL, Allanson JE. Quantitative approach to identifying abnormal variation in human face exemplified by a study of 278 individuals with five craniofacial syndromes. Am J Med Genet. 2000;91:8-17.

27. Farkas LG, Deutsch CK. Anthropometric determination of craniofacial morphology. Am J Med Genet. 1996;65:1-4.

28. Allanson JE, O`Hara P, Farkas LG, Nair RC. Anthropometric craniofacial pattern profiles in Down Syndrome. Am J Med Genet. 1993;47:748-52.

29. Farkas LG, Hreczko TM, Katic MJ. Craniofacial norms in North American Caucasians from birth (one year) to young adulthood. In: Farkas LG, editor. Anthropometry of the head and face. $2^{\text {th }}$ ed. New York: Raven Press; 1994. p. 241-312.

30. Farkas LG, Ngiim RC, Venkatadri G. Racial and ethnic morphometry differences in the craniofacial complex. In: Farkas LG, editor. Anthropometry of the head and face. $2^{\text {th }}$ ed. New York: Raven Press; 1994. p. 201-18.

31. Sforza C, Grandi G, Pisoni L, Di Blasio C, Gandolfini M, Ferrario VF. Soft tissue facial morphometry in subjects with Moebius syndrome. Eur J Oral Sci. 2009;117:695-703.

32. Sokol RJ, Chik L, Martier SS, Salari V. Morphometry of the neonatal fetal alcohol syndrome face from 'snapshots'. Alcohol Alcohol Suppl. 1991;1:531-4

33. Morihisa O. Análise facial fotográfica e suas proporções. Revisão da Literatura. 2006. [consultado 2013 Dez 03]. Disponível em http://www. ibict.metodista.br/tedeSimplificado/tde busca/arquivo.php?...1886.

34. Morihisa O. Avaliação comparativa entre a agradabilidade facial, proporção áurea e padrão facial. 2006. Dissertação de Mestrado na Faculdade de Odontologia da Universidade Metodista de São Paulo. Brasil. [consultado 2013 Dez 03]. Disponível em http://www.ibict.metodista.br/ tedeSimplificado/tde busca/arquivo.php?...38 


\section{Apresentação do Método Anátomo-Clínico de} Faciometria Directa em Crianças com Objectivos Propedêuticos

Acta Med Port 2014:27:458-466

Publicado pela Acta Médica Portuguesa, a Revista Científica da Ordem dos Médicos

Av. Almirante Gago Coutinho, 151

1749-084 Lisboa, Portugal.

Tel: +351218428 215

E-mail: submissao@actamedicaportuguesa.com

www.actamedicaportuguesa.com

ISSN:0870-399X | e-ISSN: 1646-0758

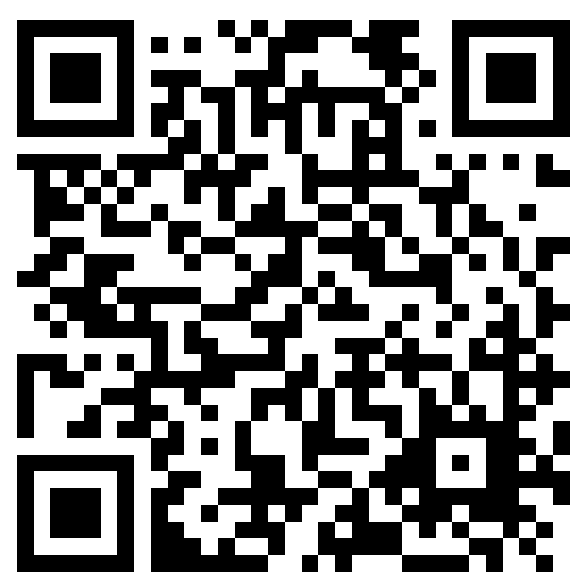

